\title{
Latin American Society of Ethnobiology's Code of Ethics
}

\author{
SOLAE Ethics Committee ${ }^{1}$, Armando Medinaceli ${ }^{1 *}$, Eréndira J. Cano ${ }^{1}$, Arturo Argueta ${ }^{1}$, and Olga Lucia Sanabria ${ }^{1}$ \\ ${ }^{1}$ Latin American Society of Ethnobiology (SOLAE), Mexico City, Mexico. \\ *manduche@gmail.com
}

Received September 21, 2017

OPEN ӘACCESS

Accepted October 8, 2017

DOI 10.14237/ebl.9.1.2018.1121

Copyright (c) 2018 by the author(s); licensee Society of Ethnobiology. This is an open-access article distributed under the terms of the Creative Commons Attribution-NonCommercial 4.0 International Public License (https://creativecommons.org/licenses/by-nc/4.0), which permits non-commercial use, distribution, and reproduction in any medium, provided the original author and source are credited.

\section{Introduction}

Since its creation in 2008, the Latin American Society of Ethnobiology (Sociedad Latinoamericana de Etnobiología-SOLAE) has hosted discussions and encouraged reflections on ethics in ethnobiological research as one of its main priorities. At the Third SOLAE Conference in La Paz, Bolivia, in 2012, members from Mexico, Bolivia, and Colombia formed an Ethics Committee to draft a SOLAE code of ethics regulating ethnobiological research and activities implemented by Latin American ethnobiologists and others who intend to undertake research in the region.

From 2012 to 2015, the Ethics Committee has held several meetings and organized sessions in which ethnobiologists, representatives from local communities, and Indigenous peoples to provide opportunities for discussion and dialogue. During this period, the Ethics Committee developed three preliminary versions of the code of ethics (versions 0 , 1, and 2). In September 2015, during the Fourth SOLAE Conference in Popayan, Colombia, we submitted a revised version for consideration by the SOLAE General Assembly. The newest version was voted on, accepted, and adopted by the General Assembly as the official SOLAE code of ethics. The new SOLAE code appeared soon thereafter in a special edition of the journal Etnobiologia (SOLAE 2016).

As part of SOLAE's commitment and intention to collaborate with ethnobiologists from other parts of the world, in 2016, SOLAE's Ethics Committee invited the Society of Ethnobiology (SoE) to cocreate a Memorandum of Understanding (MOU) between the societies. SOLAE's goal for the MOU is to strengthen and encourage communication and collaboration between members of both societies. This MOU was approved by SoE and SOLAE and was signed on May 13, 2017 during the 40th Annual Meeting of the Society of Ethnobiology in Montreal, Canada. Following the elaboration of the SOLAE code, we began the process of implementing the code of ethics in collaboration with institutions and local people. As part of this initiative, and as a follow-up to the consultation process, in February 2016 the First International Forum for the Defense and Protection of the Collective Biocultural Heritage, in Villa de Tututepec, Oaxaca, Mexico (Primer Foro Internacional por la Defensa y Protección de la Herencia Biocultural Colectiva en Villa de Tututepec, Oaxaca, México) took place with the participation of diverse Indigenous groups from Mexico and Colombia. More recently, the Universidad de San Carlos of Guatemala, non-profit organizations in Guatemala and Mexico, and some local (community) governments are considering implementation of the SOLAE code of ethics as part of their regulations.

Table 1 shows how the SOLAE code of ethics has developed through time. In the future, the SOLAE Ethics Committee will continue our discussions, dialogues, and revisions to the current version of the code of ethics.

The Ethics Committee is constantly looking for additional opportunities to open spaces for dialogue, discussion, and implementation of the SOLAE code of ethics. As part of our commitment to share and engage in dialogue with other communities and ethnobiologists that work or would like to engage in research in Latin America, in the following paragraphs we present the English version of SOLAE's code of ethics (without its original introductory section). We hope this publication is a step forward towards the 


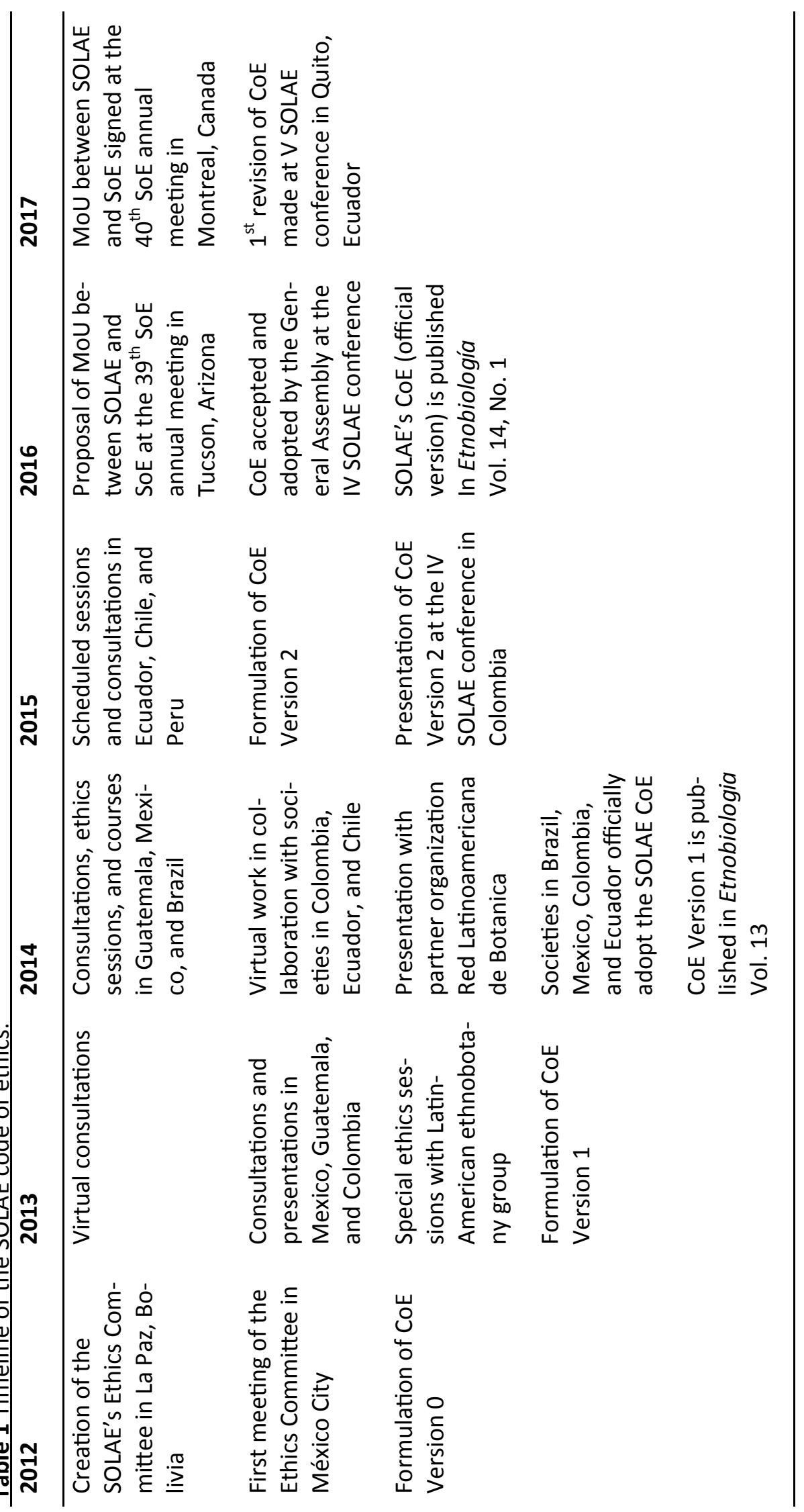


goal of benefitting local communities and Indigenous peoples in Latin America.

Comments, questions, and suggestions are welcome, and should be directed to the coordinators of the SOLAE's ethics committee: Armando Medinaceli (manduche@gmail.com) and Eréndira Cano (erecano@gmail.com).

\section{Principles}

Commitments

1. All people engaged in ethnoscientific research who are members of the Latin American Society of Ethnobiology (SOLAE) commit to become familiar with, respect, comply with, enforce, spread, and stimulate discussion about the principles in this code of ethics in their professional work.

2. All members of SOLAE participating in research and ethnoscientific work recognize the historically unjust circumstances and the economic, political, cultural, social, and educational oppression experienced by indigenous peoples and local, traditional, and afro -descendent communities of Latin America and the Caribbean. Thus, we commit to respect, safeguard, recognize, and value the integrity of local identities, as well as to disseminate their cultural richness, promote respect for their culture, the right to safeguard territories, and the collective biocultural patrimony belonging to the indigenous peoples and local, traditional, and afro -descendant communities from Latin America and the Caribbean.

\section{Responsibilities}

3. Prior to the start of any study/research, a process of obtaining Free Prior and Informed Consent will be carried out with individuals, communities, or associations with whom the study will be conducted, recognizing and respecting local, regional, and traditional regulatory systems, internal or customary laws, and in general any locally recognized regulatory system. This agreement must accompany the study or investigation from its beginning. It shall provide objective, clear, and accurate information in local terms and language to individuals, communities, and local authorities of the region regarding the project or program to be carried out, the experience and specialties of the researcher, colleagues, or research team, as well as the institution to which they belong and entities providing support and resources.

4. Before starting ethnoscientific research, researchers should know and familiarize themselves with the cultural context of the study location and region, as well as local normative systems, to conduct their work in accordance with these norms, responding to local demands, particularities, or needs. Prior agreements made with local or regional authorities and organizations regarding ethnoscientific research activities (biological, ethnobotanical, ethnomycological, ethnozoological, ethnoagricultural, ethnobiological, ethnoecological, among others) will be respected in the event they already exist.

5. It is a mandatory responsibility that as their research develops, ethnoscientists offer constant and accessible information (based on the principle of Free Prior and Informed Consent) about the progress and stages of the study or investigation.

Rights

6. It is recognized that populations with whom research is undertaken have the rights, according to their cultural patterns, to preserve their privacy, protect secrets about their history, religion, cosmovision, and politics involving natural resources, as well as to enforce respect for their local norms regarding access to knowledge, sacred practices, sites, natural resources, spirits, and in general, the behaviors and practices of specialty knowledge holders.

7. Researchers must be conscientious with regard to the applicability and impacts of the investigation and will consult villages, communities, and people with whom research is conducted about its importance, applicability, and short, middle, and long term impacts, as well as legal or customary means to grant, deny, or revoke any approval, consent, or permit for undertaking research. Parents or legal guardians will be responsible for granting consent for the participation of children and adolescents during the research process, in accordance with the laws regarding children and adolescents in each region or country.

8. If there exist intentions of commercial use of research results, they should be explicitly stated in prior signed agreements with the population involved, and they should be framed according to local regulations and norms, as well as national 
and international laws, which should favor the defense of traditional knowledge associated with biological and genetic resources. At no point should the researchers make use of ethnoscientific information for their own, institutional or private economic benefit without prior written and signed authorization.

9. If a collaborative research project is established by mutual agreement, according to the conditions mentioned above, local participants should be included as co-authors, co-researchers, collaborators, or experts. The outdated term "informant" should be replaced by more appropriate terms according to the functions performed in new projects.

\section{Dissemination and Communication}

10. All means of disseminating obtained ethnoscientific information must be included in prior consensual agreements with the people involved. These agreements must be made in collective participation spaces through consensus by the local population and researchers and formulated with clarity and precision in the medium, format, and language that is locally acceptable.

11. It must be guaranteed to all people involved in ethnoscientific research that such collaboration will not be used to cause any prejudice or discrimination against individuals, the community, or third parties.

12. The right to collaborative intellectual property and, therefore, to authorship and co-authorship of cultural productions and territory by people and populations is recognized. Publication, dissemination, and authorship of data should be determined through consultation and prior consent with communities within the study region, according to the local norms, signed or documented using locally accepted formats, and following national and international norms regarding ancestral peoples, their intellectual production, collection of genetic varieties, and registration of patents, as well as forms and means of disseminating traditional knowledge, with or without commercial ends.

13. Ethnoscientists have the right to maintain the confidentiality of their sources and not disseminate information without authorization by the people and local communities who participate in the research.
14. Care will be taken at all times to ensure an ethnobiological investigation does not put at risk any access, protection, usufruct, property, conservation, or safeguarding, as appropriate, of the territory and tangible and intangible property of the group or community that participates in the research.

15. Relationships within the research team, as well as with people from indigenous villages and local communities, should promote respect, equality, and good treatment, and avoid any discriminatory conduct or violence based on gender, social status, belonging to ancestral groups, ethnic selfidentity, affective preference, age, nationality or precedence, religious belief, profession or occupation, health condition, or different physical abilities.

16. In cases where people from local communities are not active participants in the ethnoscientific research, the study should have clear and precise mechanisms for obtaining permission, sharing, and exchanging information that are previously and collectively agreed upon and registered in signed documents in accordance with locally accepted mediums and formats.

17. In the case of research undertaken within disputed territories, ethnobiologists should recognize efforts to defend ancestral territories and the collective biocultural patrimony and commit to not impede them.

Acceptance, Adoption, and Updating

18. This SOLAE code of ethics should be promoted for adoption by its member ethnobiologists, other scientific societies, non-governmental organizations, as well as academic institutions that undertake ethnobiological work in Latin America. Likewise, knowledge and acceptance of this code of ethics will be promoted and disseminated among local, indigenous, peasant, and afrodescendant communities.

The SOLAE code of ethics will be consulted and reviewed by a committee between conferences and revisions or ratifications presented for approval by the SOLAE General Assembly during each new SOLAE conference.

\section{References Cited}

SOLAE (Sociedad Latinoamericana de Etnobiología). 2016. Código de Ética. Etnobiologia 14(1). 